\title{
Miniaturized Minkowski-lsland Fractal Microstrip Antenna Fed by Proximity Coupling for Wireless Fidelity Application
}

\author{
I Putu Elba Duta Nugraha ${ }^{* 1}$, Indra Surjati ${ }^{2}$, Syah Alam ${ }^{3}$ \\ ${ }^{12}$ Graduate Programme of Electrical Engineering, Faculty of Industrial Technology, Universitas Trisakti, \\ Jl. Kyai Tapa No. 1 Grogol, Jakarta 11440 \\ ${ }^{3}$ Electrical Engineering Department, Faculty of Engineering, Universitas 17 Agustus 1945 \\ JI. Sunter Permai Raya No. 1, Jakarta 14350 \\ Corresponding author, e-mail: elba.nugraha@gmail.com¹, indra@trisakti.ac.id², \\ syah.alam@uta45jakarta.ac.id ${ }^{3}$
}

\begin{abstract}
This paper proposed a new design of Minkowski Island microstrip antenna fed by proximity coupling with partial ground plane. The design was consisted of two layers of substrate, on the top substrate was the antenna patch and on the bottom substrate was the proximity feed line and the partial ground. At the first stage, the normal square patch antenna was mainly designed. Then, the Minkowski patch antenna was designed using $1^{\text {st }}$ iteration technique and $2^{\text {nd }}$ iteration technique. The Minkowski fractal shape slot was embedded in the center of the patch to form a Minkowski Island patch antenna. Using the Minkowski Island fractal technique, the dimension of the patch can be reduced up to $58.7 \%$. The proximity feed line in this design was used to increase the impedance bandwidth, and from the measurement the impedance bandwidth of the proposed antenna was $240 \mathrm{MHz}$ with return loss of $-24.54 \mathrm{~dB}$ and VSWR of 1.126.
\end{abstract}

Keywords: Minkowski Island, fractal, proximity feed, microstrip antenna, Wi-Fi

Copyright (c) 2017 Universitas Ahmad Dahlan. All rights reserved.

\section{Introduction}

Demands of devices with small sizes are more and more increasing and therefore corresponding antennas must be designed on small size and light weight structures. The microstrip patch antenna is the best selection for the researcher because it is a low cost material, lightweight and also easy to fabricate [1]. Several new techniques are combined to enhance the performance of the antenna and to save space. These techniques include reconfigurable antenna arrays [2,3], peripheral slits, and fractal geometries. This is to cater the high demand of high end user nowadays, especially on the Wireless Local Area Network (WLAN) or Wi-Fi application.

One of the best ways to miniaturize antennas and improve their properties is to shape their basic structures in the form of fractal geometries, which are based on self-similar configurations. Consequently, fractal antennas can benefit from their space-filling properties to occupy a small volume by quite a long electrical length, so that the operating frequency decreases and effective antenna miniaturization is achieved [4]. Fractal geometry shape can be composed of multiple copies of the similarity structure with different size and scale. Minkowski shape is one of the fractal geometry that can be applied for this purpose. At [5] Minkowski-like pre-fractal curve is deployed to achieve size reduction up to $57.15 \%$, but this design uses a direct coupling technique that is relatively difficult to fabricate. The other example of fractal shape is Koch [6], resulting in patch reduction up to $73.5 \%$, but this design is limited to simulation and not fabricated. Minkowski Island is the improvement technique of the Minkowski fractal by embedding the Minkowski slot in the center of the antenna patch. Minkowski Island in combination with partial ground techniques are applied at $[7,8]$ to achieve substrate reduction up to $22.45 \%$, but no patch size reduction is obtained.

However, these microstrip antennas also have some basic disadvantages, namely, limited gain, low power, and narrow bandwidth of only about $2 \%-5 \%$. To overcome the narrow 
bandwidth, has been introduced the indirect or electromagnetic coupling. The advantage of this technique is that it can widen the bandwidth and can reduce the soldering process [9]. Research conducted by [10] using the electromagnetic coupling in the form of microstrip feed line, and the resulting bandwidth of this fractal antenna is up to $7 \%$. Another research done by [11] using fractal antenna fed with coplanar waveguide (CPW), a type of electromagnetic coupling with the bandwidth generated up to $8 \%$. The research done by [12] using fractal antenna fed with proximity coupling and the resulting bandwidth is up to $9 \%$. Proximity feed technique itself has another advantage that when it is manufactured, the antenna is easy to optimize by shifting the position of the feed line.

Based on previous study results, it can be inferred that the fractal geometry method can reduce the antenna size. Therefore this paper proposed a new design of miniature Minkowski Island fractal microstrip antenna fed by proximity feed line to increase the impedance bandwidth.

\section{Antenna Design}

The design of the proposed antenna is made based on two layers of FR4 substrate with relative permittivity $(\boldsymbol{\varepsilon} r)$ of 4.3 , substrate thickness $(\boldsymbol{h})$ of $1.6 \mathrm{~mm}$ each, and loss tangent $(\tan \delta)$ of 0.0265 . Patch will be positioned on the top layer substrate, while the proximity feed line and partial ground will be on the bottom layer substrate.

The dimensions of the square patch antenna can be obtained from the equations below. With $\boldsymbol{a}$ is the side length of the square, $\boldsymbol{f}_{r}$ is the resonance frequency of $\mathrm{Wi}-\mathrm{Fi}(2400 \mathrm{MHz})$ and $\boldsymbol{c}$ is the speed of light $\left(3 \times 10^{8} \mathrm{~m} / \mathrm{s}\right)$.

$$
\begin{aligned}
& \varepsilon_{\text {eff }}=\frac{\varepsilon_{\mathrm{r}}+1}{2}+\frac{\varepsilon_{\mathrm{r}}-1}{2}\left(1+\frac{10 \mathrm{~h}}{\mathrm{a}}\right)^{-\frac{1}{2}} \\
& \boldsymbol{a}_{\text {eff }}=\mathrm{a}\left[1+0.824 \frac{\mathrm{h}\left(\varepsilon_{\text {eff }}+0.3\right)\left(\left(\frac{\mathrm{a}}{\mathrm{h}}+0.262\right)\right.}{\mathrm{a}\left(\varepsilon_{\mathrm{eff}}-0.258\right)\left(\left(\frac{\mathrm{a}}{\mathrm{h}}+0.813\right)\right.}\right] \\
& \boldsymbol{f}_{r}=\frac{\mathrm{c}}{2 \mathrm{a}_{\text {eff }} \sqrt{\varepsilon_{\text {eff }}}}
\end{aligned}
$$

Side length of the square patch $(a)=35 \mathrm{~mm}$ is obtained from the equations. Then the Minkowski curve can be characterized by the iteration factor, shown in Figure 1. Zero iteration $\left(\boldsymbol{N}_{0}\right)$ is represented by the normal patch without any scraped out of copper. First iteration $\left(\boldsymbol{N}_{1}\right)$ shows that four rectangular shapes of copper had been cut from the patch. Second iteration $\left(\boldsymbol{N}_{2}\right)$ shows another eight rectangular had been cut from the patch. Minkowski Island is the improvement technique of the Minkowski fractal of embedding the Minkowski slot in the center of the antenna patch $\left(\boldsymbol{P}_{\boldsymbol{0}}\right)$. Finally, the overall patch size reduction is achieved in $\boldsymbol{P}_{\boldsymbol{1}}$. The dimension of the Minkowski Island fractal antenna generation are given in Table 1 with the same size was use for both substrates.

Table 1. Dimension of Minkowski Island Fractal Antenna Generation

\begin{tabular}{ccccccc}
\hline \multirow{2}{*}{ Part } & \multirow{2}{*}{ Symbol } & \multicolumn{5}{c}{ Dimension (mm) } \\
& $N_{0}$ & $N_{1}$ & $N_{2}$ & $P_{0}$ & $P_{1}$ \\
\hline Substrate width & $\mathrm{W}_{\mathrm{s}}$ & 37 & 37 & 37 & 37 & 30 \\
\hline Substrate length & $\mathrm{L}_{\mathrm{s}}$ & 48 & 48 & 48 & 48 & 38 \\
\hline Patch side & $\mathrm{a}$ & 35 & 35 & 35 & 35 & 22.5 \\
\hline Feed width & $\mathrm{W}_{\mathrm{f}}$ & 2.6 & 2.6 & 2.6 & 2.6 & 2.6 \\
\hline Feed length & $\mathrm{L}_{\mathrm{f}}$ & 17 & 17 & 17 & 17 & 17 \\
\hline Ground width & $\mathrm{W}_{\mathrm{g}}$ & 30 & 30 & 30 & 30 & 30 \\
\hline Ground length & $\mathrm{L}_{\mathrm{g}}$ & 7 & 7 & 7 & 7 & 7 \\
\hline Stub length & $\mathrm{L}_{\text {stub }}$ & 5 & 5 & 5 & 5 & 6 \\
\hline
\end{tabular}

TELKOMNIKA Vol. 15, No. 3, September 2017 : $1119-1126$ 


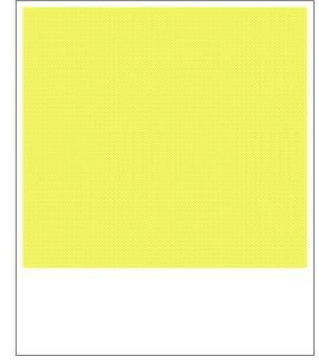

(a)

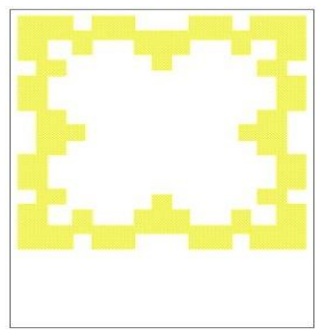

(d)

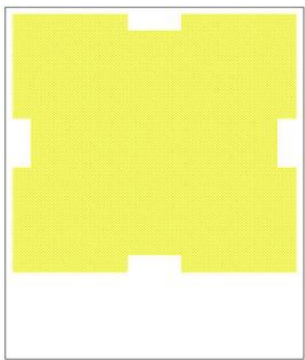

(b)

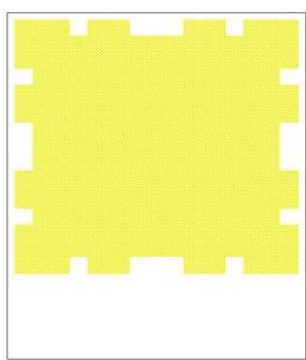

(c)

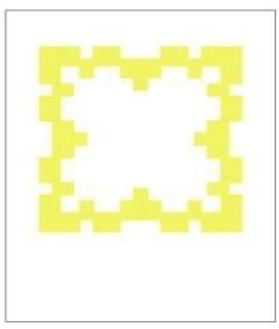

(e)

Figure 1. Generation procedure of Minkowski Island patch antenna, (a) Basic square patch microstrip antenna $\left(\boldsymbol{N}_{0}\right)$, (b) $1^{\text {st }}$ iteration $\left(\boldsymbol{N}_{1}\right)$, (c) $2^{\text {nd }}$ iteration $\left(\boldsymbol{N}_{2}\right)$, (d) Minkowski Island patch $\left(\boldsymbol{P}_{\mathbf{0}}\right),(\mathrm{e})$ Miniaturized Minkowski Island patch $\left(\boldsymbol{P}_{\mathbf{1}}\right)$

Figure 2 exhibits the configuration of final design $\left(\boldsymbol{P}_{\mathbf{1}}\right)$ of the proposed antenna. The Minkowski patch part dimension is $22.5 \mathrm{~mm}$ width $\times 22.5 \mathrm{~mm}$ length, located at the top layer substrate. The antenna fed by proximity coupling using a $50 \mathrm{Ohm}$ connector to enlarge the impedance bandwidth. The feed line is located at the bottom substrate with $17 \mathrm{~mm}$ in length and $2.6 \mathrm{~mm}$ width. The stub length of the feed line is $6 \mathrm{~mm}$. The bottom substrate also consists of partial ground with the dimension of $30 \mathrm{~mm}$ width $\times 7 \mathrm{~mm}$ length, which is used to optimize the return loss of the antenna.

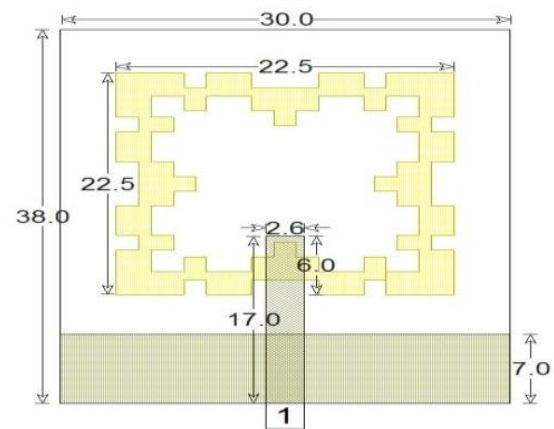

(a)

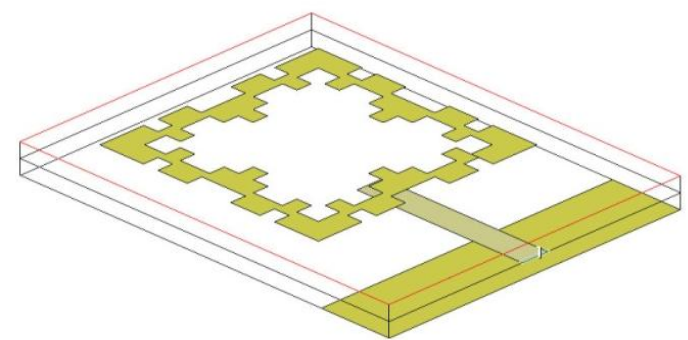

(b)

Figure 2. Configuration of the final design $\left(\boldsymbol{P}_{\mathbf{1}}\right)$, (a) Dimension of the proposed antenna, (b) 3D layout of the proposed antenna

\section{Results and Analysis}

The simulation results of return loss and VSWR from different generation of Minkowski Island patch antenna are shown in Figure 3. 


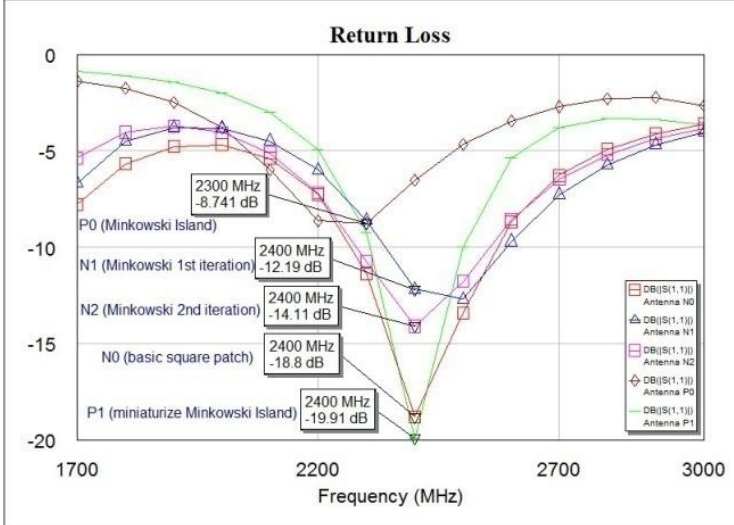

(a)

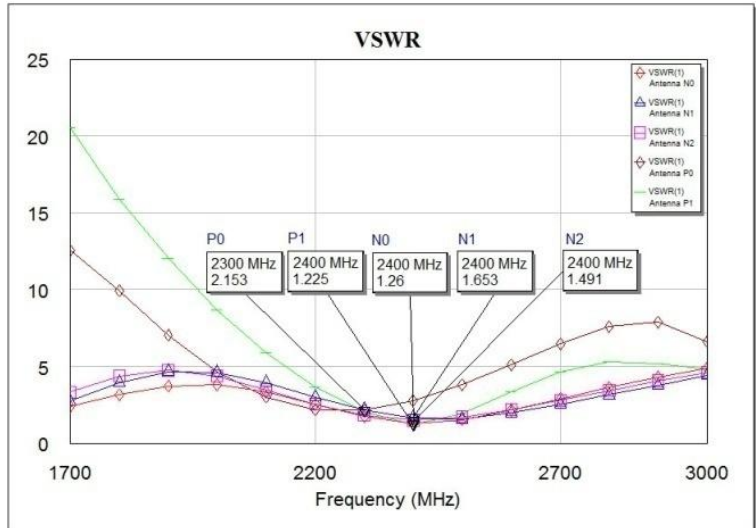

(b)

Figure 3. Simulation results of (a) Return Loss value and (b) VSWR value

The resonant frequency of design $\boldsymbol{N}_{0}$ was at $2400 \mathrm{MHz}$ with return loss of $-18.80 \mathrm{~dB}$ and VSWR of 1.260 and bandwidth of this design was $305 \mathrm{MHz}$ at the range frequency of 2267 $\mathrm{MHz}$ until $2572 \mathrm{MHz}$. The resonant frequency of $1^{\text {st }}$ iteration design $\boldsymbol{N}_{1}$ was at $2400 \mathrm{MHz}$ with return loss of $-12.19 \mathrm{~dB}$, VSWR of 1.653 and bandwidth of $251 \mathrm{MHz}$ at the range frequency between $2339 \mathrm{MHz}$ to $2590 \mathrm{MHz}$. The resonant frequency of $2^{\text {nd }}$ iteration design $\boldsymbol{N}_{2}$ was at 2400 $\mathrm{MHz}$ with return loss of $-14.11 \mathrm{~dB}$, VSWR of 1.491 and bandwidth of $276 \mathrm{MHz}$ at the frequency between $2279 \mathrm{MHz}$ and $2555 \mathrm{MHz}$. According to the theory, the resonant frequency of design $\boldsymbol{P}_{0}$ should be lower than basic square geometry because of the longer electrical length of fractal geometry, and indeed it was decrease to $2300 \mathrm{MHz}$ but could not achieve matching condition with only $-8.741 \mathrm{~dB}$ of return loss and VSWR of 2.153. The design then optimized in $\boldsymbol{P}_{\boldsymbol{1}}$ by reducing the size of fractal patch and then the resonant frequency was return to $2400 \mathrm{MHz}$ with return loss of $-19.91 \mathrm{~dB}$ and VSWR of 1.225 and bandwidth of $193 \mathrm{MHz}$ at the range frequency of $2307 \mathrm{MHz}$ until $2500 \mathrm{MHz}$. The overall simulation results of all antenna generation are summarized in Table 2. Clearly from Table 1 and Table 2 results, $\boldsymbol{P}_{\boldsymbol{1}}$ was chosen as the final design by achieving the best overall parameter including size, resonant frequency, return loss, VSWR, bandwidth, and input impedance.

Table 2. Simulation Results of Minkowski Island Fractal Antenna Generation

\begin{tabular}{cccccc}
\hline Design & $\begin{array}{c}\text { Resonant Frequency } \\
f_{r}(\mathrm{MHz})\end{array}$ & $\begin{array}{c}\text { Return Loss } \\
(\mathrm{dB})\end{array}$ & $\begin{array}{c}\text { VSWR } \\
\begin{array}{c}\text { Bandwidth }(\mathrm{MHz}) \\
f_{1}-f_{2}(\mathrm{MHz})\end{array}\end{array}$ & $\begin{array}{c}\text { Input impedance at } f_{r} \\
(\Omega)\end{array}$ \\
\hline$N_{0}$ & 2400 & -18.80 & 1.260 & $\begin{array}{c}305 \\
2267-2572\end{array}$ & 47.439 \\
$N_{1}$ & 2400 & -12.19 & 1.653 & $\begin{array}{c}251 \\
2339-2590\end{array}$ & 39.866 \\
$N_{2}$ & 2400 & -14.11 & 1.491 & 276 & $2279-2555$ \\
$P_{0}$ & 2300 & -8.741 & 2.153 & - & 52.356 \\
$P_{1}$ & 2400 & -19.91 & 1.225 & 193 & 85.690 \\
\hline
\end{tabular}

A laboratory prototype structure of design $\boldsymbol{P}_{1}$ was fabricated to validate the simulated results. The antenna was fitted with the standard $50 \mathrm{Ohm}$ connector having a center pin diameter of $1.2 \mathrm{~mm}$ as seen in Figure 4. The return loss $\left(\mathrm{S}_{11}\right)$ was measured using $300 \mathrm{kHz}-20$ $\mathrm{GHz}$ Vector Network Analyzer (VNA). An anechoic chamber was used to measure the radiation properties of the fabricated antenna. The measurement setup to measure return loss and radiation pattern are shown in Figure 5(a) and 5(b) respectively. 


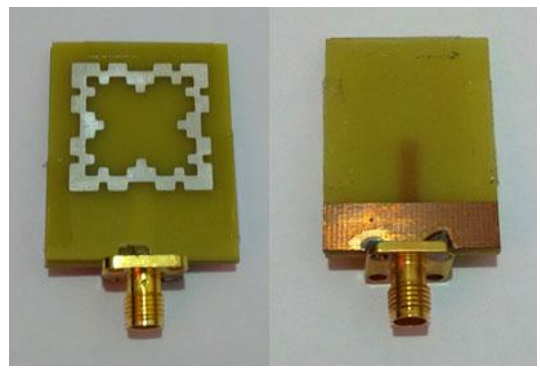

Figure 4. Photograph of the fabricated antenna prototype from design $\boldsymbol{P}_{\boldsymbol{1}}$

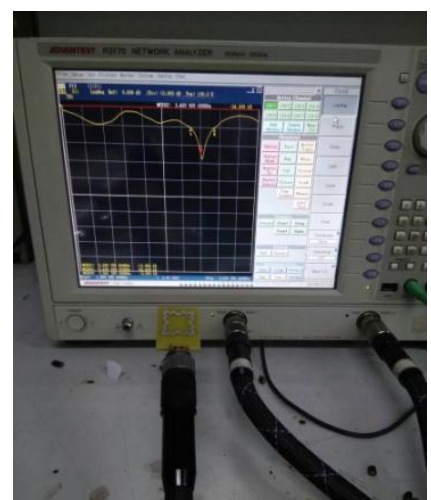

(a)

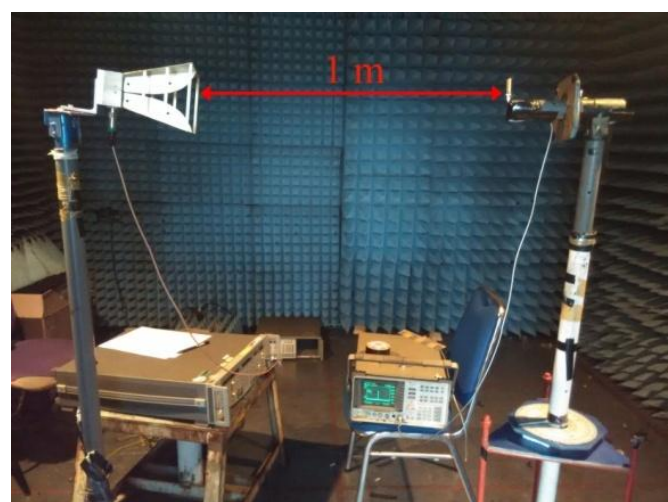

(b)

Figure 5. Measurement setup (a) Return loss measurement with VNA, (b) Radiation pattern measurement in the anechoic chamber

The measurements result of return loss and VSWR that have been done in the laboratory can be seen in Figure 6 and Figure 7. The comparison between simulated and measured parameter characteristics of proposed antenna is shown in Table 3 and the graphic comparison of Return Loss and VSWR are shown in Figure 8 and Figure 9 respectively. It is evident from these results that the measured results are different (actually better) from the simulation. This can be caused by antenna fabrication which is not $100 \%$ equal to the dimensions of the simulation, the imperfection of SMA connector soldering process, the imperfection process of joining the two substrates so there is an air gap between them, as well as the loss of the connectors and coaxial cable. The measurement results indicate that the proposed antenna can be a suitable design for Wi-Fi application.

Table 3. Comparison between Simulated and Measured Parameter of the Proposed Antenna

\begin{tabular}{ccc}
\hline Parameter & Simulation & Measurement \\
\hline Resonant Frequency $\left(f_{r}\right)$ & $2400 \mathrm{MHz}$ & $2400 \mathrm{MHz}$ \\
Return Loss & $-19.91 \mathrm{~dB}$ & $-24.54 \mathrm{~dB}$ \\
VSWR & 1.225 & 1.126 \\
Bandwidth & $193 \mathrm{MHz}$ & $240 \mathrm{MHz}$ \\
$f_{1}-f_{2}$ & $2307 \mathrm{MHz}-2500 \mathrm{MHz}$ & $2300 \mathrm{MHz}-2540 \mathrm{MHz}$ \\
Input impedance & $41.562 \Omega$ & $45.854 \Omega$ \\
\hline
\end{tabular}




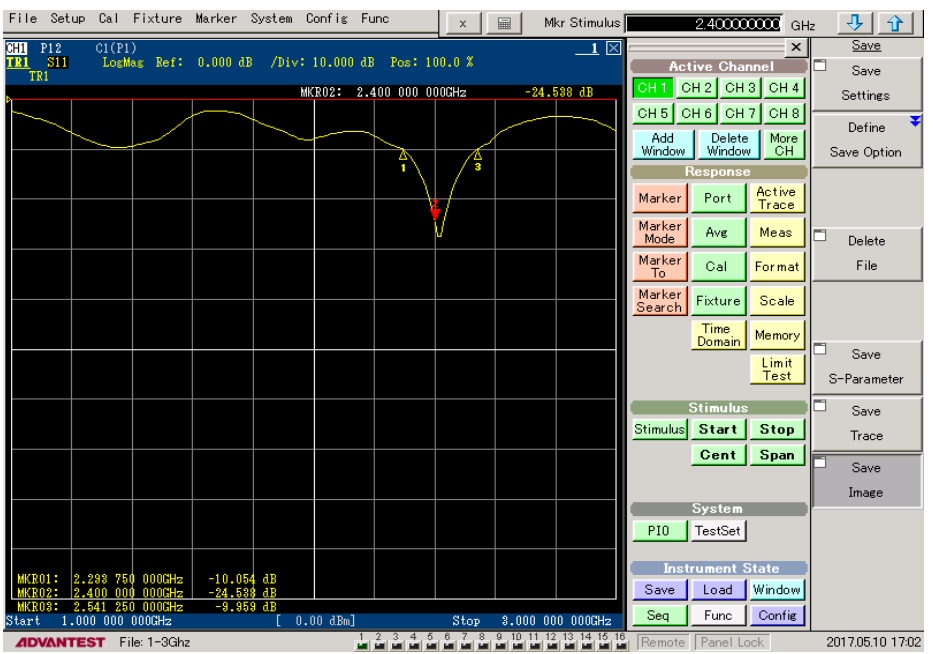

Figure 6. Measurement of return loss

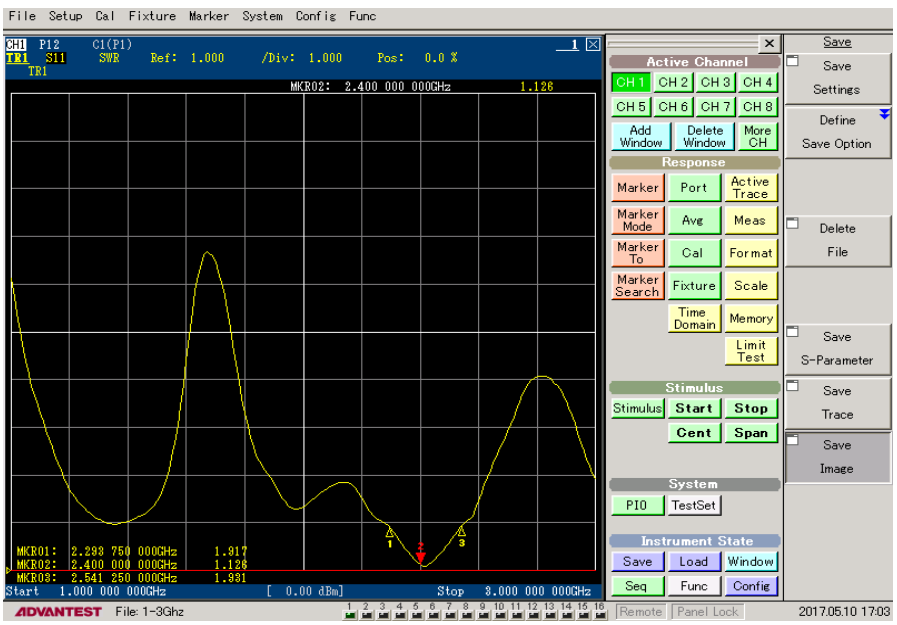

Figure 7. Measurement of VSWR

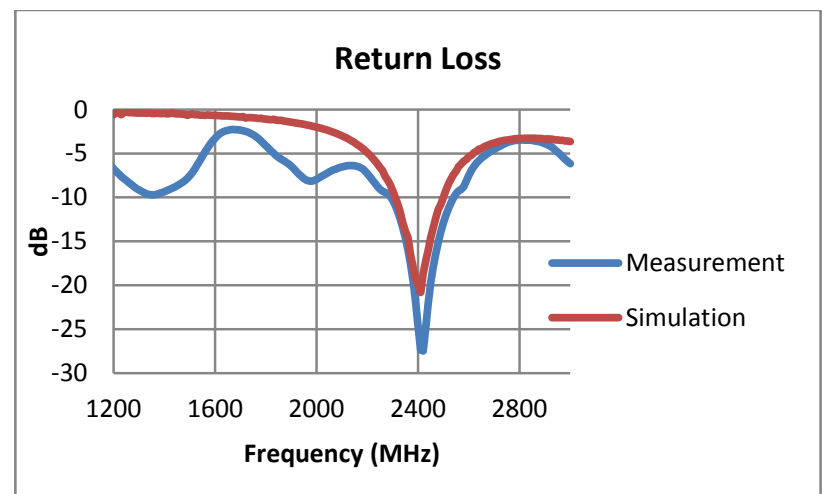

Figure 8. Comparison between measurement and simulation results of return loss 


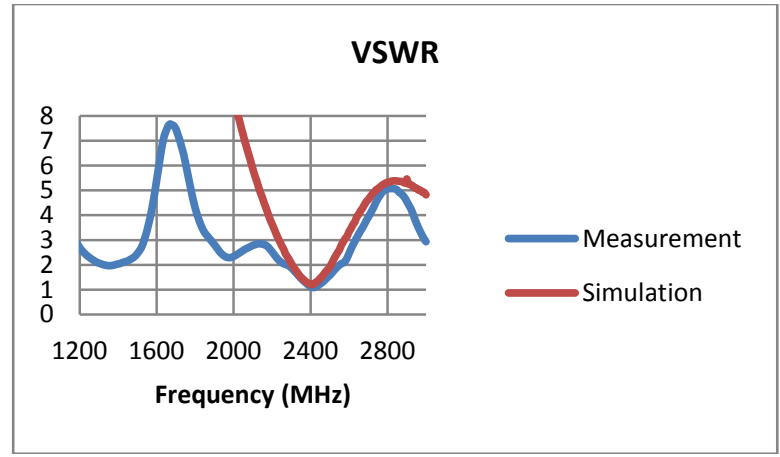

Figure 9. Comparison between measurement and simulation results of VSWR

The radiation pattern measurement was conducted in the anechoic chamber by using a horn antenna (model SAS-200/571 frequency $700 \mathrm{MHz}-18 \mathrm{GHz}$ ) as the reference antenna. The RF generator and spectrum analyzer were set to $2400 \mathrm{MHz}$. The far field distance between the reference antenna and measured microstrip antenna has been calculated as 1 meter. The measured microstrip antenna was rotated with a $10^{\circ}$ increment from $0^{\circ}$ to $350^{\circ}$. Figure 10 shows the radiation pattern measurement result from the proposed antenna design with Half Power Beamwidth (HPBW) of $30^{\circ}$.

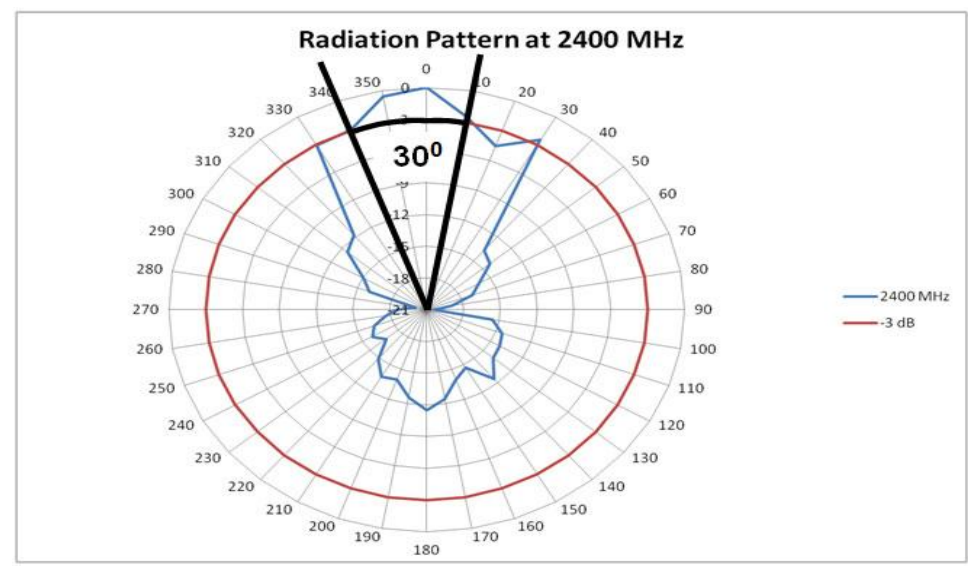

Figure 10. Radiation pattern of the proposed antenna

The gain of the proposed Minkowski Island fractal antenna $\left(\boldsymbol{G}_{T}\right)$ was calculated by using the following formula.

$$
G_{T}[d B i]=G_{0}[d B i]+P_{T}[d B i]-P_{0}[d B i]
$$

With $\boldsymbol{P}_{T}$ is the power received by the measured antenna, $\boldsymbol{P}_{\boldsymbol{O}}$ is the power received by the reference antenna, and $G_{0}$ is the gain of the reference antenna. Given the measurement value of $\boldsymbol{P}_{\boldsymbol{T}}=-22.77 \mathrm{dBi}, \boldsymbol{P}_{\boldsymbol{0}}=-14.24 \mathrm{dBi}$ and $\boldsymbol{G}_{\boldsymbol{0}}=12 \mathrm{dBi}$, the calculated gain of the proposed antenna at $2400 \mathrm{MHz}$ is $3.47 \mathrm{dBi}$.

\section{Conclusion}

By using the $1^{\text {st }}$ iteration technique and $2^{\text {nd }}$ iteration technique of Minkowski fractal to the basic square patch then embedding Minkowski fractal slot to form the Minkowski Island shape, the size of patch area and substrate area can be reduced up to $58.7 \%$ and $35.8 \%$ respectively to produce a compact antenna that is suitable for Wi-Fi application. The proposed 
microstrip antenna is also optimized for bandwidth and return loss by applying proximity feed in combination with partial ground technique. The fabricated prototype of Minkowski Island fractal antenna has been measured and it is observed that the result from the measurement are better than the simulation with resonant frequency of $2400 \mathrm{MHz}$, return loss of $-24.54 \mathrm{~dB}$, VSWR of 1.126, impedance bandwidth of $240 \mathrm{MHz}$, and gain of $3.47 \mathrm{~dB}$. From the simulation and measurement results, they show that the application of Minkowski Island fractal to the patch of basic microstrip antenna can be used to reduce the size of the overall antenna significantly without sacrificing the performance of the antenna.

\section{References}

[1] Garg R, Bhartia P, Bahl I, Ittipiboon A. Microstrip Antenna Design Handbook. Norwood: Artech House, Inc. 2001.

[2] Rocca P, Morabito AF. Optimal Synthesis of Reconfigurable Planar Arrays with Simplified Architectures for Monopulse Radar Applications. IEEE Transactions on Antennas and Propagation. 2015; 63(3): 1048-1058.

[3] Isernia T, Massa A, Morabito AF, Rocca P. On the Optimal Synthesis of Phase-only Reconfigurable Antenna Arrays. The 5th European Conference in Antennas and Propagation (EUCAP). Rome. 2011: 2074-2077.

[4] Oraizi H, Hedayati S. Application of Z-type and Hilbert Fractal Structures for Multiband and Circularly Polarized Microstrip Antennas. IEEE 15th Mediterranean Microwave Symposium (MMS). Lecce. 2015: 1-4.

[5] Kumar S, Vishwakarma DK. Compact Circularly Polarized Slits-Loaded Microstrip Patch Antenna with Symetric-Fractal Boundary. IEEE-APS Topical Conference on Antennas and Propagation in Wireless Communications (APWC). Cairns. 2016: 34-37.

[6] Ihamji M, Abdelmounim E, Zbitou J, Bennis H, Latrach M. Novel Design of a Miniature Fractal Microstrip CPW Fed Antenna for RFID Reader. International Conference on Wireless Networks and Mobile Communications (WINCOM). Fez. 2016: 95-98.

[7] Ahmad BH, Nornikman H, Aziz MA, Othman MA, Othman AR. Tri-band Minkowski Island Patch Antenna with Complementary Split Ring Resonator at the Ground Plane. Conference on Microwave Techniques (COMITE). Pardubice. 2013: 46-51.

[8] Ahmad BH, Nornikman H. Fractal Microstrip Antenna with Minkowski Island Split Ring Resonator for Broadband Application. IEEE International RF and Microwave Conference (RFM). Penang. 2013: 214-218.

[9] Pozar DM, Schaubert DH. Microstrip Antennas: the Analysis and Design of Microstrip Antennas and Arrays. Hoboken: John Wiley \& Sons. 1995.

[10] Santos MG, Teixeira PA, Carleti M, Ribeiro JA. Microstrip Wideband Antennas with Different Fractals Geometries. International Workshop on Telecommunications (IWT). Santa Rita do Sapucai. 2015: 16.

[11] Dinesh V, Karunakar G. Analysis of Microstrip Rectangular Carpet Shaped Fractal Antenna. International Conference on Signal Processing and Communication Engineering Systems (SPACES). Guntur. 2015: 531-535.

[12] Prajapati PR, Srinivasulu M, Kartikeyan MV. Realization of Circular Polarized Microstrip Antenna with Arc-slot Fractal Geometry. International Conference on Microwave, Optical and Communication Engineering (ICMOCE). Bhubaneswar. 2015: 158-161. 